\title{
Esquistossomose no Brasil: ensinar versus educar
}

\author{
Schistosomiasis in Brazil: teaching versus \\ education
}

Marcos Rogério Capello Sousa ${ }^{\mathrm{I}}$

\author{
PALAVRAS-CHAVE \\ - Educação. \\ - Saúde. \\ - Esquistossomose. \\ - Sociedade. \\ - Currículo.
}




\section{INTRODUÇÃO}

Apesar da evolução na capacidade humana de promover saúde, seja a partir das conquistas no campo da medicina e áreas correlatas, seja devido à melhora nas condições materiais da humanidade, algumas doenças antigas continuam a acometer o homem novo, do século 21.

A esquistossomose, por exemplo, ainda é um problema médico sanitário brasileiro grave, causado pelo Schistosoma mansoni, verme da classe dos trematóides. Esse nome é uma homenagem ao pai da medicina tropical, Sir Patrick Manson (1844-1922), embora parte da morfologia do parasita seja atribuída ao médico baiano Manuel Augusto Pirajá da Silva (1873-1961), daí também o nome doença de Manson-Pirajá da Silva.

A partir de fatos do cotidiano de médicos, alunos e professores da área da saúde, não só da medicina, podemos estabelecer uma reflexão e uma discussão críticas sobre o modo como a medicina em seu conjunto - ensino e prática - tem sido realizada.

Em dezembro de 2006, dois adolescentes, um de 12 e outro de 13 anos, foram internados no Hospital da PUC Campinas com diagnóstico confirmado de esquistossomose (pesquisa de ovos nas fezes positiva). Ambos se queixavam de cefaléia, dor abdominal, febre, diarréia e vômitos. Um deles apresentava os sintomas havia mais de dez dias, enquanto o outro havia três dias. O adolescente com sintomatologia mais arrastada evoluiu com aparecimento de icterícia e dispnéia, e necessitou de investigação pormenorizada pois se suspeitou de sepse.

Após período de internação e investigação que durou em média cinco dias, pôde-se confirmar que os adolescentes apresentavam antecedentes pessoais similares: banhos na mesma lagoa, na periferia de Campinas, junto com amigos domiciliados na mesma região e que apresentaram sintomas semelhantes, porém foram acompanhados noutros serviços da cidade. Após receberem o antiparasitário preconizado, passaram a ser seguidos por seus respectivos médicos, pediatras e infectologistas, e a vigilância epidemiológica foi notificada.

O contato com estes casos nos reportou a um outro, ocorrido em 1995, porém de necropsia, do mesmo serviço. Tratava-se de um adolescente de dez anos que fora admitido na UTI-infantil com quadro clínico de choque séptico e morreu em 22 horas. Esse adolescente apresentava, já havia alguns dias, quadro clínico de cefaléia, vômitos e dor abdominal que evoluiu com o aparecimento de púrpura disseminada. Seu irmão apresentava pesquisa de esquistossomose positiva (ovos nas fezes). O estudo necroscópico revelou a presença de nódulos esquistossomáticos com processo inflamatório agudo associado, disseminados por quase todos os órgãos. Embora a evolução letal seja infrequente no leque de possibilidades de apresentação/evolução clínica desta doença, neste caso admitimos tratar-se de esquistossomose com toxemia (fase aguda) e evolução fatal, pois, além da compatibilidade entre a clínica (choque séptico) e a etiologia (esquistossomose), toda a investigação microbiológica (vírus, bactérias e fungos) foi negativa.

Sabemos que, para a disseminação desta doença (infecções e reinfecções), é essencial a presença do parasita (nas fases ovo, miracídio, cercária), dos hospedeiros intermediários (caramujo) e definitivos (homem), e da água. Também já se sabe há décadas ${ }^{1}$ que são crianças e adolescentes os que mais podem se infectar no primeiro decênio de vida devido aos banhos nas lagoas. Todas estas informações, além do ciclo de infestação humana, os livros de Infectologia, Parasitologia, Clínica Médica, Pediatria, etc. confirmam, de forma mais ou menos detalhada, há 50 anos.

Os livros atuais continuam a reproduzir este conteúdo com detalhamento variável, mas nem todos ressaltam que há mais de meio século a doença se dissemina a partir da migração de populações infectadas que, ao chegarem ao destino, estabelecem relações precárias com o meio ambiente-por exemplo, moradia em locais onde não há tratamento de água e esgoto. No caso da esquistossomose, é fundamental a contaminação da água com fezes que contenham os parasitas (ovos) e que acaba sendo usada pelos próprios migrantes e moradores para fins variáveis, inclusive o lazer em banhos nas típicas "lagoas de coceira".

Neste caso, os livros da área da saúde continuam a dar pouca importância aos moldes a partir dos quais se estabelecem as relações entre o homem e a natureza, o que seria decisivo para se conhecer não só a fisiopatogênese da doença, mas também sua "sociopatogênese". Assim, até hoje, a partir desta base limitada de conhecimentos é que são delineadas e priorizadas estratégias de promoção de saúde. E, igualmente, o que se vê é que vários problemas de saúde - e não só a esquistossomose aqui usada para discussão, reflexão e crítica - são abordados superficialmente e reduzidos ao campo das ações predominantemente biológicas, que, por sua vez, inspiram ações formativas, mas nem sempre radicalmente educativas.

Baseado em Veronesi ${ }^{1}$, na década de 1960 o tratamento medicamentoso considerava quando e quais pacientes deveriam ser tratados com antimoniais e até o uso de drogas endovenosas. Também se discutia o tratamento cirúrgico para os casos crônicos, como portadores de hipertensão porta, cor pulmonale, etc.

Nesta obra de infectologia ${ }^{1}$, o tratamento da esquistossomose ocupa 5 páginas do capítulo. São destinadas 4 páginas para etiologia, 2 para epidemiologia, 4 para patologia, 27 para clínica, 4 para fisiopatologia clínica e 3 para diagnóstico clínico e labora- 
torial. Destina-se apenas meia página ao quesito profilaxia, que aborda questões como melhoria das condições materiais de vida das populações, saneamento básico, engenharia sanitária e urbanização, educação (campanhas de educação e prevenção à doença), nível de escolaridade e renda da população acometida, e o significado do desenvolvimento econômico também como forma de progresso social e controle da doença para as regiões afetadas.

Por vários motivos - entre outros, talvez para se adequarem às linhas editoriais e às regulamentações do mercado -, os livros atuais restringem a abrangência da respectiva área do conhecimento, como no caso de especialidades além da infectologia, e, por respeitarem a intenção do autor em ser sucinto, acabam por tratar determinado tema de forma parcial, sem evidenciar sua complexidade. No caso da esquistossomose, por exemplo, destinam-se ao assunto pouco mais de duas páginas, e à profilaxia apenas duas linhas ${ }^{2}$.

Não está em discussão neste texto a liberdade do autor e o enfoque que cada um dá a determinado assunto. Afinal, a web é exemplo claro da pluralidade de opiniões sobre um mesmo tópico. Discute-se aqui o juízo ou o critério científico e pedagógico que emerge periodicamente de determinado objeto e a partir do qual os conhecimentos que lhe são pertinentes adquirem importância, central ou periférica, e relevância no contexto da formação profissional em detrimento de outros conhecimentos. Nesta perspectiva, o que estaria ocorrendo no âmbito da formação profissional na área da saúde para que, decorridos mais de 40 anos entre um livro e outro, os moldes da relação homem-natureza, algo decisivo para a disseminação da doença, sejam tratados de forma rudimentar? O que haveria com a educação e a assistência à saúde e a competência de seus promotores formais?

É oportuno lembrar que esta mesma imprensa acadêmica e científica, escrita e/ou da web, reserva espaço para a discussão sobre o tratamento com antiparasitários de uso oral versus vacina antiesquistossomose $\mathrm{e}^{3,4}$.

Na perspectiva de um processo educativo que inclua a crítica e a reflexão como objetivos da formação de um profissional, será que os indivíduos atualmente preparados para trabalhar na área da saúde podem atingir outro nível de compreensão e desenvolvimento intelectual sem abordar questões ligadas à esquistossomose, ou mesmo a outras doenças, como: quem eram os migrantes da década de 1950 e quem são os migrantes do século 20 no Brasil? Por que migram? Como uma doença que na década de 1950 era prevalente em regiões carentes, como o Nordeste brasileiro, e apenas esboçava uma tendência para se estender às regiões do Sul-Sudeste do País em decorrência de correntes migra- tórias está presente no estado mais próspero da união e em particular em suas regiões metropolitanas? Onde estão as falhas no esquema de prevenção e tratamento destes pacientes? Será que um problema crônico e grave dessa magnitude pode ser resolvido somente a partir dos profissionais da área da saúde e de posse de um arcabouço teórico similar ao de 40 anos atrás?

Será que tem sido suficiente a abordagem teórica, ainda genérica e superficial, da relação entre alguns problemas de saúde crônicos e as condições materiais de vida da população (saneamento básico, educação, tratamento de água, alimentação, lazer, transporte, etc.)? No contexto da sociedade mundial do século 20, o debate sobre velhos e graves problemas não mereceria aprofundamento, principalmente em se tratando de países em desenvolvimento, como o Brasil? Será que como educadores temos nos preocupado em conhecer-ensinar o que separa a esquistossomose da década de 1960 daquela encontrada noutros locais no século 21? Será que sabemos, radicalmente, o que vem ocorrendo nos últimos 50 anos no Brasil para então poder explicar a "transmissão" da esquistossomose para uma região metropolitana do Sudeste? Quais são os moldes desta nova relação homem-natureza?

E uma questão que parece fundamental diante de certo desinteresse e apatia estudantil em relação ao conteúdo dos currículos da área da saúde é a seguinte: será que os novos aprendizes, privados destes conhecimentos "marginais" que talvez fossem esclarecedores, não se sentem precocemente frustrados e impotentes diante da falta de bons resultados e dos problemas enfrentados por seus mestres há mais de 40 anos? Será que não temem reproduzir este enfoque da esquistossomose daqui a mais meio século e reduzir a importância das raízes desta doença, tendo apenas como inovação a vacina antiesquistossomose? Será que a tão defendida prática multidisciplinar-interdisciplinar, mais restrita à reunião de especialistas de várias áreas da saúde, terá competência técnica para resolver problemas desta magnitude?

A infecção esquistossomática é apenas um exemplo de como é possível fazer uma extrapolação sobre o modo como algumas moléstias - não só infectoparasitárias, mas também crônico-degenerativas, metabólicas, cardiovasculares, etc. - têm acometido a população brasileira. É claro que tais problemas, a partir de uma outra abordagem mais ampla e complexa como a proposta neste espaço, não serão resolvidos da noite para o dia, e nem é isso que se espera do processo educativo quando bem fundamentado.

A complexidade dos problemas de saúde não tem sido devidamente considerada, exceto quanto ao aprofundamento-detalhamento dos aspectos físico-químicos, que são transferidos ao campo 
da biologia, como a engenharia genética, a biologia molecular, etc. assunto que também merece uma reflexão e discussão crítica! Isto faz com que se menosprezem outras características tão ou mais importantes do mesmo problema em relação à profilaxia da esquistossomose, como vimos nos livros de Medicina, o que resulta numa brutal limitação do entendimento deste quebra-cabeça. As consequências parecem óbvias: decorridos 50 anos, a esquistossomose continua sendo um problema de saúde pública no Brasil, mas, dentro do modelo acadêmico-científico contemporâneo, tem sido enfrentado com pesquisas no campo da imunologia-engenharia genética a fim de se criar uma vacina.

Merece atenção o fato de que o modelo atual de ensino-assistência à saúde, mesmo com a perspectiva do enfoque multidisciplinar, da expansão da assistência primária e da sua relevância como modelo para formação profissional, ainda não conseguiu modificar a influência do modelo prévio hospitalocêntrico, flexneriano, dando provas, senão da sua ineficiência, ao menos da sua insuficiência: no caso da esquistossomose, registravam-se 4 milhões de brasileiros na década de $1950 / 60^{1}$ e, atualmente, são 12 milhões de doentes ${ }^{2}$. Será que não haveria necessidade de uma discussão mais ampla, com envolvimento dos educandos, sobre o que pode ter ocorrido ou ainda estar ocorrendo no que se refere à abordagem desta doença?

Parece-nos que os modelos de ensino-prática, na medicina e noutras áreas da saúde, orientados a partir da massificação da assistência primária dos últimos 30 anos e que adotam a perspectiva multidisciplinar ainda não têm tido fôlego para enfrentar tais situações. A velocidade com que aparecem novos problemas de saúde e/ou reaparecem velhos problemas noutros locais e que se associam a outros novos supera a capacidade de enfrentamento e resolução do sistema de saúde, aqui sempre pensado como integração da educação e da assistência.

Parece ser imperativa uma análise histórica, contextualizada, desses e de outros problemas de saúde, precisamente brasileiros, que permita à academia refletir sobre os fundamentos teóricos ainda usados para a formação de recursos humanos na área da saúde. Têm sido evitados questionamentos sobre fluxo migratório das populações e sua relação com a urbanização das cidades metropolitanas; ecologia; saneamento; lazer; o modo como vem se dando, nos últimos 50 anos, a formação da economia brasileira e a constituição da população brasileira. Tais assuntos, entre outros tantos, fogem da esfera das ciências naturais e da biologia, mas talvez tenham igual ou maior importância na elaboração de diagnósticos mais complexos e numa proposição coerente sobre como promover saúde.

A tarefa mais difícil talvez seja mostrar à sociedade, leiga e acadêmica, que nestes últimos 50 anos, em particular no Brasil, estivemos, em grande parte, modelando educação-assistência para promover saúde orientados por uma visão limitada, atentos a uma situação que exibe apenas a "sua ponta do iceberg". Educar implica, no mínimo, aceitar o desafio de explorar a porção escondida do iceberg.

\section{REFERÊNCIAS}

1. Veronesi, R. Esquistossomose mansônica. In: Doenças Infecciosas e Parasitárias. 2 ed. Rio de Janeiro: Guanabara Koogan;1962. p. 645-702.

2. Murahovschi J. Grandes endemias: esquistossomose. In: Pediatria : Diagnóstico + Tratamento. 6 ed. São Paulo: Sarvier; 2003. p.735-737.

3. Homma A, Martins RM, Jessourum E, Oliva O. Desenvolvimento tecnológico:elo deficiente na inovação tecnológica de vacinas no Brasil. História ciênc saúde Manguinhos. 2003;10:671-696.

4. Katz N. Dificuldades no desenvolvimento de uma vacina para Esquistossomose Mansoni. Rev soc brás med tropical. 1999;32:705-711.

\section{CONFLITO DE INTERESSES}

Declarou não haver

\section{ENDEREÇO PARA CORRESPONDÊNCIA}

\author{
Marcos Rogério Capello Sousa \\ Faculdade de Medicina - PUC Campinas \\ Av. John Boyd Dynlop, s/n \\ Jd. Ipaussurama - Campus II \\ CEP. 13059-900 Campinas - SP \\ E-mail: mimcapello@puc-campinas.edu.br
}

